\title{
Electrochemical nanosensors: advances and applications
}

This article was published in the following Dove Press journal:

Reports in Electrochemistry

2 February 2016

Number of times this article has been viewed

\author{
Seán Barry \\ Alan O'Riordan \\ Nanotechnology Group, Tyndall \\ National Institute, University College \\ Cork, Cork, Ireland
}

\begin{abstract}
The use of nanomaterials for the development of electrochemical nanosensors has attracted growing interest in recent years. The enhanced chemical and physical properties arising from discrete nanoelectrode devices or microelectrodes modified with nanomaterials make these devices an attractive option for the improvement of current electroanalytical applications. This review discusses and describes advances made since 2010 in the application of nanomaterials in a number of major fields, namely: health, security, law enforcement, environment, and food safety.

Keywords: electrochemistry, nanowire, nanoparticles, nanotubes, graphene, voltammetry, impedance
\end{abstract}

\section{Introduction}

Nanotechnology is a rapidly growing area of research due to the remarkable characteristics of nanomaterials. When compared to bulk materials, nanomaterials have been found to possess enhanced physical and chemical characteristics including, but not limited to, thermal, ${ }^{1}$ optical, ${ }^{2}$ magnetic,,${ }^{3,4}$ plasmonic, ${ }^{5,6}$ and catalytic ${ }^{7}$ properties. These enhanced features have led to the incorporation of nanomaterials into electrochemical sensing systems as a means of improving current sensor technologies. Noble metal ${ }^{8}$ and carbon ${ }^{9}$ materials have often been favored for these applications because of their chemical inertness and biocompatibility. Other materials of interest include silicon, ${ }^{10}$ cadmium telluride, ${ }^{11}$ nickel, ${ }^{12}$ palladium, ${ }^{13}$ gallium nitride,${ }^{14}$ and metal oxides ${ }^{15-17}$ While more common applications of nanomaterials relate to the modification (or decoration) of larger electrodes, there are also examples of single nanoparticles ${ }^{18}$ or highly ordered arrays of nanoparticles ${ }^{19}$ being used independently as electrodes.

Individual electrodes with nanoscale dimensions which offer fundamental improvements over micro- and macroelectrodes ${ }^{20}$ are also being developed at a growing rate. Single gold nanowires fabricated on silicon substrates using electron beam (e-beam) lithography have been shown to exhibit enhanced mass transport due to radial diffusion. ${ }^{21}$ Steady-state currents seen at these electrodes allow for the use of increased scan rates and, as a result, shorter analysis times. ${ }^{22}$ The double layer capacitance at these electrodes also shows an improvement over micro/macroelectrodes due to their very small surface area. Thus, nanoelectrodes possess much smaller cell time constants allowing them to respond much faster to changes in the applied potential. As a consequence of their reduced surface area, nanoelectrodes also exhibit low ohmic drop compared to larger electrodes. By reducing or removing this potential
Correspondence: Alan O’Riordan

Nanotechnology Group, Tyndall National Institute, University College Cork, Lee Maltings, Mardyke Parade, Cork, Ireland Tel +353214906403

Email alan.oriordan@tyndall.ie submit your manuscript $\mid$ www.dovepress.con

Dovepress

http://dx.doi.org// 0.21 47/RIE.S80550 (c) (i) (9) 2016 Barry and 0'Riordan. This work is published and licensed by Dove Medical Press Limited. The full terms of this license are available at https://www.dovepress. com/terms.php and incorporate the Creative Commons Attribution - Non Commercial (unported, v3.0) License (http://(creativecommons.org/licenses/by-n/3.0.0). By accessing

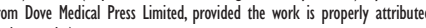
For permission for commercial use of this work, please see paragraphs 4.2 and 5 of our Terms (https://www.dovepress.com/terms.php). 
source of experimental error, it is possible to perform experiments in highly resistive solutions and may permit for the simplification of any experimental setup by the use of a two electrode cell. Potential fabrication methods and the benefits of on-chip electrodes and their geometries have already been discussed in a recent review. ${ }^{23}$

Improvements in laser pulling technology has also led to the miniaturization of disk shaped electrodes with benefits for applications involving: in vivo monitoring of neurotransmitters ${ }^{24}$ with a reduced risk of cerebral damage, the monitoring of processes within a cell, ${ }^{25}$ the accurate delivery of drugs ${ }^{26}$ or for electrochemical characterization of nanostructures using scanning electrochemical microscopy. ${ }^{27}$

The vast array of electrode geometries, materials, and fabrication techniques available has resulted in an expansive field of possible applications. This review focuses on some of the major areas of interest, namely health, security and law enforcement, environment, and agri-food (more general information on the benefits and recent advances in nanoelectrodes can be found in a number of recent reviews). ${ }^{28,29}$ Due to the versatility of nanoelectrochemical sensors, they also have applications in more niche areas of research; an example being the use of nanoelectrode ensembles for immunoglobulin Y (IgY) detection as a means of identifying egg yolk as a pigment in tempera paintings. ${ }^{30}$ This review aims to give an in-depth description of advances in applications of electrochemical nanosensor applications in health, security, law enforcement, environment, and food safety within the last 6 years.

\section{Health}

A major driving force behind the development of nanoelectrochemical devices is the demand for point of care devices. ${ }^{31}$ Nanoelectrode devices offer an attractive option in this field due to their small footprint and potential for high sensitivity. As a result of the versatility and variety of nanoelectrode devices, they have been employed for the detection of a large range of medically relevant analytes ranging from small molecules such as dopamine ${ }^{32-34}$ and histamine ${ }^{35}$ to larger, more complex targets like bacteria ${ }^{36}$ or pharmaceutical drugs. ${ }^{37,38}$

Enzyme based biosensors have long been of interest because of the selectivity of enzymes as biorecognition elements. ${ }^{39}$ This selectivity combined with the recent developments in nanoelectrochemistry has led to the emergence of highly specific and sensitive biosensors. Discrete single nanowire electrodes fabricated using a hybrid e-beam/optical lithography process have been used to detect glucose at $10 \mu \mathrm{M}$ levels using a mediated detection method. ${ }^{40}$ In this approach, glucose oxidase is dissolved in an electrolyte solution containing the electrochemical redox molecule ferrocene monocarboxylic acid ( $\mathrm{FcCOOH})$. The $\mathrm{FcCOOH}$ acts as a mediator and assists with electron transfer upon the addition of glucose to the system which results in an increase in the current observed using cyclic voltammetry $(\mathrm{CV})$ as the glucose is oxidized by the glucose oxidase. Normal blood glucose levels are between 4.2 and $6.4 \mathrm{mM}^{41}$; by achieving a detection limit significantly lower than these levels, it allows for the possibility of pain free glucose detection from other bodily fluids including saliva. ${ }^{42-44}$ The sensitivity of these discrete electrodes has been attributed to radial diffusion of the mediator molecule to the electrode surface. This results in enhanced mass transport which, when combined with the enhanced heterogeneous electron transfer rates observed at nanoelectrodes, ${ }^{45}$ is a distinct advantage over macro electrodes which exhibit limited currents due to planar diffusion.

The decoration of macro or microelectrodes with nanomaterials is a common strategy for improving sensor performance with carbon nanotubes, ${ }^{46}$ nanorods, ${ }^{47}$ and gold nanoparticles ${ }^{48}$ all finding applications for glucose sensing. The incorporation of these nanomaterials increases the roughness and surface area of larger electrodes, while they may also exhibit favorable electrocatalytic properties toward electroactive compounds. These improved characteristics lower the detection limits while also simplifying detection methods by removing the need for mediator molecules. Many non-mediated enzymatic biosensors rely on the oxidation or reduction of hydrogen peroxide, a common by-product from oxidase enzyme reactions. While gold macro electrodes are known to have poor performance in relation to peroxide detection, this can be overcome by depositing layers such as Prussian blue (PB) which is electrocatalytic toward peroxide oxidation/reduction. Unfortunately, the use of PB at nanoelectrodes is limited by the poor stability of the PB film due to the similar scale of electrode size and layer thickness. Clausmeyer et al overcame this limitation by fabricating pulled pipette carbon nanoelectrodes ${ }^{49}$ containing a nanocavity and electrodepositing the PB film within the cavity. The use of the cavity increases the film stability as any part of the film which becomes dissolved or detached is trapped within the cavity and quickly redeposited on the nanoelectrode. Although this does create added electrode stability, sensor response times are diminished as the analyte must diffuse through a narrow capillary to access the electrode surface within the nanocavity. Nanomaterials have been found to possess electrocatalytic properties for the oxidation or reduction of hydrogen peroxide. Nanoskived nanowires ${ }^{50}$ 
and nanowire stacks ${ }^{51}$ offer solutions involving fabricated nanoelectrodes, while a large variety of nanoparticles have been utilized to increase the activity of a selection of macro electrodes. ${ }^{15,19,52,53}$ This enhancement is due to the factors already discussed earlier (improved mass transport, electron transfer, and surface area).

A major limitation of enzyme based biosensors is the enzymes themselves. Free enzymes suffer from thermal instability, susceptibility to attack from proteins, and high sensitivity to denaturing agents. ${ }^{54}$ While these drawbacks may be minimized by enzyme immobilization, they cannot be fully accounted for and suitable storage conditions $\left(\mathrm{eg}, 4^{\circ} \mathrm{C}\right.$ in phosphate buffer) are also required to maintain enzyme activity. Careful selection of nanomaterials can allow for enzyme free detection, thus increasing the potential stability and lifetime of the sensor. Nickel oxide nanowalls, ${ }^{55}$ nanoporous copper modified with multi-walled carbon nanotubes (MWCNT), ${ }^{56}$ and gold nanoparticle-decorated silicon nanowire arrays ${ }^{10}$ have all been shown to successfully detect glucose at low concentrations. These nanostructures provide enhanced catalytic activity toward the oxidation of glucose, eliminating the need for the addition or immobilization of glucose oxidase. This allows these sensors to maintain their activity for an extended time without any prohibitive storage requirements while still maintaining a high selectivity for glucose.

As well as enzymes, antibodies are popular biorecognition units used in the development of biosensors. ${ }^{57}$ Nanoelectrochemical immunosensors usually involve the immobilization of an antibody on either discrete nanowires or on larger electrodes modified with nanomaterials. Singh et $\mathrm{a}^{58}$ developed gold interdigitated electrodes (IDEs) with submicron separation for the detection of CRP. Finite element analysis was performed to give an indication of the optimal interelectrode spacing and electrode height. The electric field in phosphate-buffered saline surrounding the electrodes was found to drastically increase for gaps under $800 \mathrm{~nm}$, while the electrode height had only a minimal effect. To support these simulations, a range of electrodes were fabricated using photolithography although the range of interelectrode spacings was restricted by the limitations of the photolithographic techniques used. Electrodes with spacings of $500 \mathrm{~nm}$, were found to have a good compromise between an enhanced electrode field and reproducibility of the fabrication process. After optimization and fabrication, these nanogap IDEs were modified with rabbit anti-human CRP polyclonal antibody. The binding event between the CRP and rabbit anti-human CRP polyclonal antibody was measured using electrochemical impedance spectroscopy (EIS) which allowed for the detection of CRP in both buffer and serum in the range of $100 \mathrm{pg} / \mathrm{mL}$ to $1 \mu \mathrm{g} / \mathrm{mL}$. The significant enhancement of electric fields by using submicron spaced IDEs coupled with the label free nature of EIS makes these methods an attractive option compared with more traditional fluorometric techniques. As such, many nanomaterials, and combinations of nanomaterials (nanoparticles, ${ }^{59,60}$ nanorods, ${ }^{61}$ carbon nanotubes, ${ }^{62}$ graphene ${ }^{63}$ ) have been used for the development of EIS based immunosensors. The incorporation of nanomaterials into these sensors has a threefold effect when compared to unmodified electrodes. First, they may provide an improved microenvironment to maintain the bioactivity of the antibodies, improving biosensor stability and performance. Nanomaterials may also improve resistive and capacitive properties of the electrode due to their high conductivity, thus leading to improved sensitivity. The increased surface area available allows for the immobilization of a larger amount of antibody compared to more conventional planar electrodes with similar geometric area.

In Figure 1, it can be seen that in order to give an indication of renal tubular injury, Hu et $\mathrm{l}^{64}$ decorated $\mathrm{Ag} @ \mathrm{BSA}$ microspheres with RBP monoclonal antibody to detect RBP using EIS and differential pulse voltammetry (DPV) as detection techniques which exhibited extremely low detection limits of 47 and $18 \mathrm{ng} \mathrm{mL}^{-1}$, respectively. These low detection limits can be attributed to the increased surface area and improved conductivity of the electrode due to the presence of the microspheres.

Voltammetric techniques are also used as stand-alone detection methods for nanoelectrochemical immunosensors. Jin et $\mathrm{a}^{65}$ used $\mathrm{CV}$ at a graphene electrode modified using magnetic microbeads to immobilize Au nanoparticles functionalized with capture antibodies to successfully detect cancer biomarkers. Elsewhere, DPV has been used for the detection of leptin in 50\% diluted serum samples at concentrations as low as $0.05 \mathrm{ng} \mathrm{mL}^{-1}{ }^{66}$ While these methods do require the use of a mediator molecule, they do have benefits in reducing analysis times. The changes in charge transfer resistance which many EIS biosensors are based upon are more apparent at lower frequencies which lead to longer analysis times, typically a number of minutes. The aforementioned voltammetric techniques can provide an adequate response within seconds.

\section{Security and law enforcement}

Recent global events have led to an increased demand for effective field tests for security screening and as a result, the 


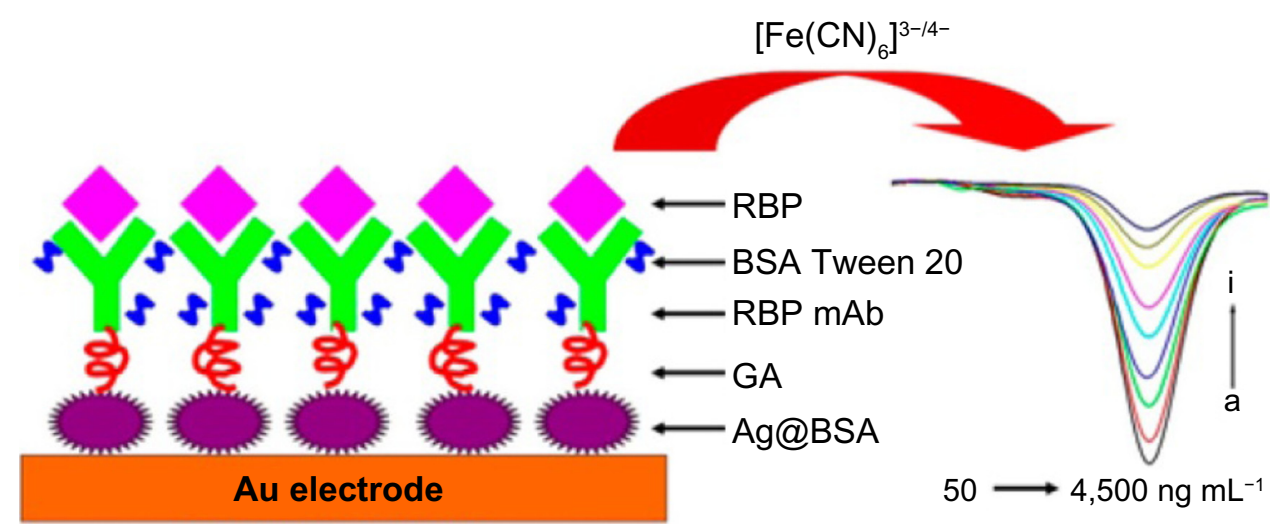

Figure I Schematic of $\mathrm{Ag} @ \mathrm{BSA}$ microspheres sensor used for renal binding protein detection and the related DPV response.

Notes: a to $\mathrm{i}=$ decreasing analyte concentrations from 50 to 4,400 ng mL-I (colours illustrate different concentrations). Reprinted with permission from Hu CY, Yang DP, Xu K, et al. Ag@BSA Core/Shell Microspheres As an Electrochemical Interface for Sensitive Detection of Urinary Retinal-Binding Protein. Analytical Chemistry. 2012;84(23): 10324-10331. ${ }^{64}$ Copyright 2012 American Chemical Society.

Abbreviations: DPV, differential pulse voltammetry; mAb, monoclonal antibody; BSA, bovine serum albumin; CNT, carbon nanotube; GA, gluteraldehyde.

use of electrochemical methods has received considerable attention for the screening of nitro containing explosives, ${ }^{67}$ illicit drugs, ${ }^{68}$ and poisons..$^{69,70}$

Nitroaromatic explosives and their related compounds are particularly suited to electrochemical detection due to the inherent redox activity of their nitro groups as the $\mathrm{NO}_{2}$ ligands are sequentially reduced to $\mathrm{NH}_{3} \cdot{ }^{71}$ The direct reduction of these compounds has been achieved using arrays of band electrodes with a width of $700 \mathrm{~nm} .{ }^{72}$ Electrodes, including integrated on-chip reference and counter electrodes, were fabricated using optical photolithography on a silicon dioxide substrate and the response of the unmodified electrodes to 3-nitrotoluene, 2,4-dinitrotoluene, 2,6-dinitrotoluene, 1,3-dinitrobenzene, and 2,4,6-trinitrotoluene in a phosphate buffer solution was investigated using CV and SWV. CV proved unable to differentiate adequately between the various nitroaromatics, while SWV showed a clear distinction between the reduction peaks of each compound (Figure $2 \mathrm{~A}$ ). Figure $2 \mathrm{~B}$ shows the results of a serial addition approach with SWV used to generate a calibration curve using military grade TNT for concentrations as low as $400 \mathrm{ng} \mathrm{mL-}{ }^{1}$, with no interference from any possible additives or stabilizers in the sample. In a similar fashion, $100 \mathrm{~nm}$ wide nanowires were also used to achieve a limit of detection (LOD) of $7 \mathrm{ng} \mathrm{mL-}{ }^{1}$ for DNT in an aqueous sample in the absence of any supporting electrolyte. ${ }^{73}$ These approaches demonstrate the superior capabilities of nanoelectrodes over larger traditional electrodes which often require modification to detect these compounds at suitably low concentrations. ${ }^{74,75}$ The fast response of these electrodes also gives them an advantage over more cumbersome traditional detection methods, while the integration of all three electrodes on a single silicon substrate

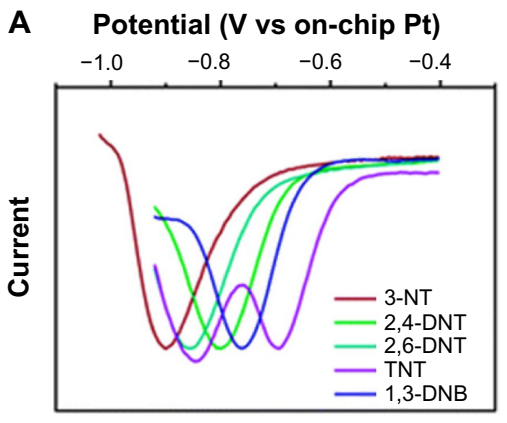

B

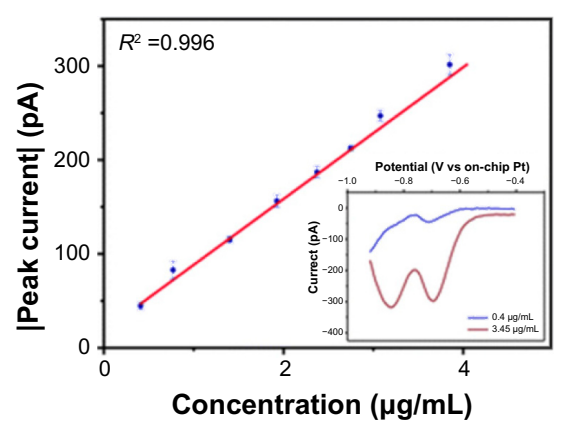

Figure 2 Electrochemical response of $700 \mathrm{~nm}$ band electrodes to various nitroaromatic compounds.

Notes: (A) Background subtracted square wave voltammograms for $50 \mu \mathrm{g} \mathrm{mL}$-1 concentrations of 3-NT, 2,4-DNT, 2,6-DNT, I,3-DNB, and TNT in phosphate buffer $\mathrm{pH}$ 6.5, Einitial: $-0.4 \mathrm{~V}$; EFinal: $-1.02 \mathrm{~V}$; amplitude: $50 \mathrm{mV}$; frequency: $10 \mathrm{~Hz}$; amplitude: $4 \mathrm{mV}$. (B) Calibration plot of TNT obtained using peak currents measured at $-671 \mathrm{mV}$. Inset: SWV voltammograms obtained for 0.40 and $3.8 \mu \mathrm{g} \mathrm{mL}^{-1}$, respectively. Adapted from Barry S, Dawson K, Correa E, Goodacre R, et al. Highly sensitive detection of nitroaromatic explosives at discrete nanowire arrays. Faraday Discuss. 2013;164:283-293.2 With permission from The Royal Society of Chemistry.

Abbreviations: NT, nitrotoluene; DNT, dinitrotoluene; DNB, dinitrobenzene; TNT, trinitrotuluene; SWV, Square Wave Voltammetry; $\mathrm{V}$, voltage; Pt, platinum. 
makes them a viable option for large scale fabrication and subsequent incorporation into field-test systems. At present, time and cost are a major inhibiting factor in the scaling of e-beam fabricated devices for widespread use.

As with health related applications, nanomaterials are often used to enhance the response seen at macro electrodes. Previously, porphyrin modified glassy carbon electrodes (GCE) have shown increased sensitivity to nitroaromatic compounds because the $\pi-\pi$ interaction between the electron rich porphyrin and electron deficient nitro-containing explosive causes a favorable electrocatalytic interaction. ${ }^{76}$ Guo et al made further use of this beneficial interaction by modifying a GCE with porphyrin functionalized graphene. ${ }^{77}$ The incorporation of graphene into the modification process resulted in a massively improved sensitivity of $2.75 \mu \mathrm{A} / \mathrm{cm}^{2}$ per pbb compared to 0.47 and $0.86 \mu \mathrm{A} / \mathrm{cm}^{2}$ per ppb at a bare $\mathrm{GCE}$ and porphyrin modified GCE, respectively. This ultratrace detection capability has been attributed to the large electroactive surface area and fast charge transfer of the electrode incorporating graphene compared to the $\mathrm{GCE} /$ porphyrin electrode. Although graphene is often incorporated with other materials in composite electrodes, ${ }^{78-80}$ bare graphene on GCE has also been shown to be highly sensitive to a range of nitroaromatic compounds, including 2,4-DNT and TNT. ${ }^{81}$ Again this can be attributed to enhanced electrocatalytic activity and high surface-area-to-volume ratio of graphene, and, as seen previously with porphyrin, strong $\pi-\pi$ interactions between nitroaromatics and the graphene surface. Other nanomaterials such as MWCNT and various metal nanoparticles have been used in similar fashion for the detection of nitroaromatic explosives $^{82,83}$ as well as more powerful plastic explosives like RDX and HMX ${ }^{84,85}$ While the improvement of many of these electrodes is due to improved electrocatalytic reduction of nitroaromatic compounds, resulting in improved peak currents and positive shifts in peak potential, the incorporation of nanoparticles into a molecularly imprinted polymer (MIP) has been shown to also increase the amount of accessible complementary cavities upon the removal of the target analyte, in this case TNT, ${ }^{86}$ compared to similar MIP electrodes without nanoparticles.

With the United Nations estimating that between 3.5\% and $7 \%$ of the world's population between the ages of $15-64$ years have tried illicit drugs and, within that age group, there are between 16 and 39 million regular drug users, ${ }^{87}$ it is obvious that improved security measures are required to stem the flow of illegal drugs across international borders and also for monitoring people who are either in treatment or on probation for drug related offences.
Cocaine has received significant research interest as it is the second most widely used illicit substance in both America and Europe. Unsurprisingly, this has led to the use of nanomaterials to enhance the signal in a wide range of aptamerbased cocaine sensors. ${ }^{88}$ Roushani and Shahdost-fard have developed a highly sensitive aptasensor which incorporates both silver nanoparticles and MWCNT ${ }^{89}$ A 2 mm GCE was modified with a composite paste of MWCNT, an ionic liquid (IL) and chitosan to provide a sensing interface which exhibited a vast surface area, good stability, prominent electric conductivity compared to unmodified electrodes, and high biocompatibility with a facile and environmentally friendly preparation procedure. Silver nanoparticles were prepared before being incubated with the $5^{\prime}-\mathrm{NH}_{2}-3^{\prime}-\mathrm{SH}_{2}$ terminated aptamer which resulted in covalent bonding of the aptamer to the nanoparticles via an $\mathrm{S}-\mathrm{Ag}$ bond. The aptamer/Ag nanoparticle solution was then added to the electrode surface for 12 hours in order to complete the construction of the cocaine aptasensor. Fully modified electrodes were immersed in concentrations of cocaine from 2 to $9 \mathrm{nM}$ and the response of the sensor was measured using DPV with riboflavin as a mediator. As the concentration of cocaine increased, the peak current observed decreased linearly due to the folding of the aptamer. The folding of the aptamer causes steric hindrance for the access of the riboflavin mediator to the electrode surface, thus inhibiting the interfacial charge transfer which results in an enhanced electron transfer resistance and, as a result, the decreased peak current.

While the previously described example was found to be highly sensitive ( $\mathrm{LOD}=150 \mathrm{pM}$ ), a limiting factor in the use of aptasensors is large background signals caused by the initial charge of the probe molecule which in turn can result in a small signal to background ratio if the analyte molecule itself has a small charge. Aptasensors may also be susceptible to false positives due to the "signal off" structure of their assays. Das et $\mathrm{al}^{90}$ have developed a neutralizer displacement assay to neutralize the effects of the probe molecule. As can be seen in Figure 3, a neutrally charged complementary strand with a number of intentional base pair mismatches is specifically bound to the probe strand, thus neutralizing its natural charge. Upon addition of the desired analyte (protein, DNA/RNA, or small molecule), the neutralizing strand is displaced in favor of the analyte due to the base pair mismatches. This new protocol applied using DPV at gold microband electrodes coated with a thin layer of nanostructured palladium was used to successfully measure cocaine at levels comparable to commercial tests. This would allow for rapid screening using lower cost and simpler instrumentation than 
A

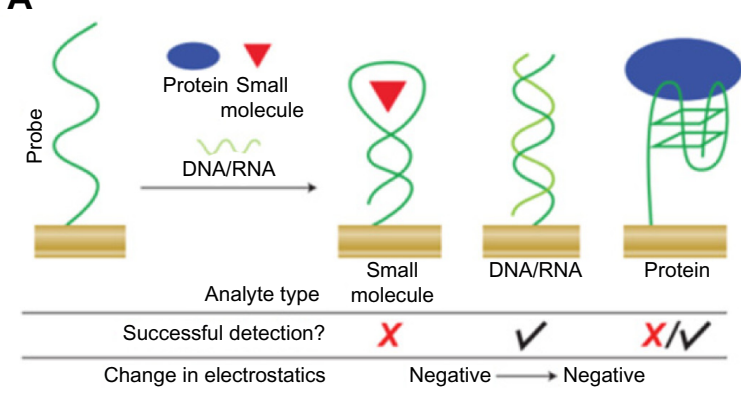

B

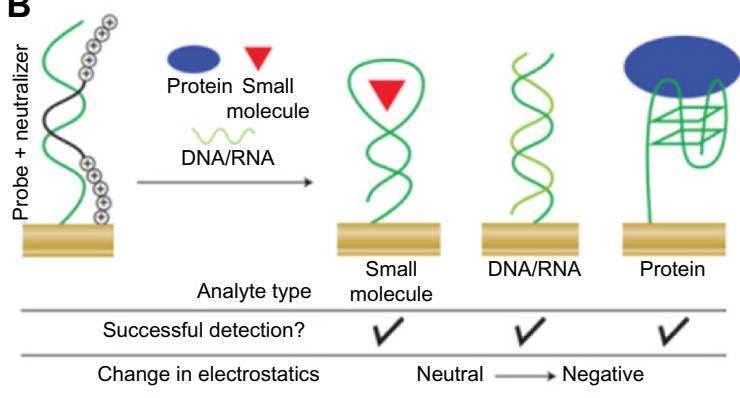

C

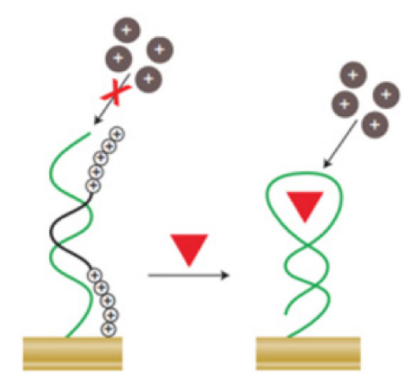

D

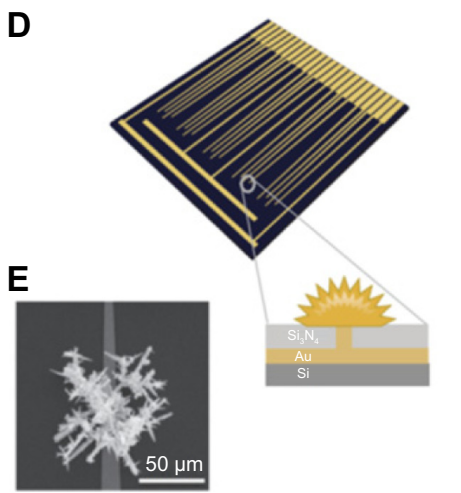

Figure 3 Summary of the NDA and sensor chips utilized for testing.

Notes: (A) In traditional electrostatic detection without NDA, only large changes in the electrostatic profile are detectable, eg, DNA/DNA binding or the binding of a highly charged protein. (B), In NDA detection, small molecules, nucleic acids, and proteins are all detectable as each one causes displacement of a neutralizer and a large change in charge. (C) The neutralizer-probe complex attenuates reporter-ion binding. The release of the neutralizer on the addition of the target changes the electrostatics to negative, which yields an increased electrocatalytic current. Schematic (D) of a sensor chip that possesses 20 nanostructured electrodes with structures as shown in (E). Reprinted with permission from Macmillan Publishers Ltd: Nature Chemistry, Das J, Cederquist KB, Zaragoza AA et al. An ultrasensitive universal detector based on neutralizer displacement. Nat Chem. 2012;4(8):642-648. Copyright 2012.90

Abbreviation: NDA, neutralizer displacement assay.

current methods. Another major benefit of this technique is that the aptamer component may be tailored to target an array of molecularly diverse samples, permitting a multiplexed approach on a single sensor chip.

Opiates are also of interest due to their highly addictive properties. While morphine itself is a concern, the detection of morphine in urine samples can also be an indicator of heroin abuse which has led Atta et al to develop a gold nanoparticle based sensor for morphine detection. ${ }^{91}$ A nanoparticle/ferrocene carboxylic acid/phthalocyanine composite was constructed on a platinum disk electrode, and by utilizing DPV an LOD of $21 \mathrm{nM}$ was achieved for the detection of morphine in dilute urine samples. While the purpose of the phthalocyanine moiety was to aid electron transfer via a central metal atom, this was further improved by the addition of the nanoparticles, with the nanoparticles acting as conduction centers in the layer to facilitate electron transfer. Interference studies showed a high selectivity for morphine over amino acid and clear separation of peaks when dopamine was also present. The use of MWCNT combined with ILs has also demonstrated the applicability of nanomaterials for the detection of morphine, reaching a detection limit of $140 \mathrm{nM}$ without the need for a mediator. ${ }^{92}$ Although phenolic compounds often cause surface fouling of electrodes, causing deterioration in electrochemical response, the MWCNT/IL mixture showed a robust resistance to fouling while maintaining its ability to promote charge transfer.

\section{Environment}

The monitoring of environmental contaminants is vital to ensure that they are at acceptable levels in our water, soil, and air to protect public health and the environment from these organic and inorganic pollutants. Pesticides are considered to be a high priority because of their high toxicity toward humans due to their effect on the central nervous system. Nanomaterials are being incorporated into procedures for removal and detection ${ }^{93,94}$ of a number of compounds to ensure that levels in surface and groundwater remain at safe levels and have negligible effects on the environment or the food chain.

Organophosphate pesticides have been extensively used across the agricultural and industrial sectors and are among the first priority group of pesticides listed in the US Food Quality Protection Act. Organophosphates operate by damaging the AChE enzyme which kills pests by impairing critical control of their nerve signals but can also have unwanted 
side effects on the human central nervous system with some compounds, such as picloram in Agent White, ${ }^{95}$ even being incorporated into mixtures for herbicidal warfare. Methyl parathion has attracted significant interest due to its acute toxicity ${ }^{96}$ with a wide variety of nanomaterials and composites of nanomaterials being applied to its detection. ${ }^{97-100}$ Although many nanomaterial based sensors offer suitable sensitivity to methyl parathion, they often lack the required selectivity for real world analysis. Fu et $\mathrm{a}^{101}$ have developed a sensitive and selective platform, utilizing a combination of nanomaterials and cyclodextrin, for the detection of methyl parathion in tap and river water. First a GCE is modified with gold nanoparticles and single wall carbon nanotubes to increase its surface area and improve conductivity. Afterward a modified $\beta$-cyclodextrin is immobilized by immersion of the electrode in solution for 12 hours. The fully prepared electrode is subsequently immersed in a methyl parathion solution where an inclusion complex is formed with the cyclodextrin, effectively acting as a pre-concentration mechanism while also improving electrode selectivity. After rinsing, electrochemical detection is performed in a buffer solution via square wave anodic stripping voltammetry, achieving a detection limit of $0.1 \mathrm{nM}$ which was significantly lower than similar cyclodextrin modified electrodes utilizing only single wall carbon nanotubes ${ }^{102}$ or graphene. ${ }^{103}$ Although this method is highly selective and sensitive, the scalability of the modified cyclodextrin synthesis is unknown which may make this unsuitable for wider use when compared to other modification techniques which utilize commercially available compounds.

Although the use of organochlorine insecticides is being restricted by legislation due to their adverse effects on the environment and human health, they still remain in the environment due to their resistance to degradation. ${ }^{104}$ Lindane ( $\gamma$-hexachlorocyclohexane) production is a source of particular concern as it is estimated that for every ton of lindane produced, there are 9 tons of toxic waste products from other isomers produced. ${ }^{105}$ Anu Prathap et al have developed a highly sensitive sensor by mounting a layer of $\mathrm{CuO} / \mathrm{MnO}_{2}$ nano-microstructures (Figure 4A-D) by evaporation. ${ }^{106}$ Mixed metal oxides have been shown to have improved electrochemical responses compared to single metal oxides, while as seen in many other examples, the use of nanostructures increases the materials' electrocatalytic capabilities. The mixed metal oxide platform was shown to be highly sensitive $\left(0.12 \mu \mathrm{A} \mu \mathrm{M}^{-1}\right.$ and lower detection limit of $4.8 \mathrm{nM}$ ) and selective to the electrocatalytic reduction of lindane with a highly linear calibration plot being obtained using DPV as shown in Figure 4E. While this method is currently limited to suitably buffered systems, Kaur et al ${ }^{107}$ have recently utilized DPV to achieve a similar detection limit (5 $\mathrm{nM}$ ) using silver nanoparticles to modify their electrode, with an improved sensitivity of $1.24 \mu \mathrm{A} \mu \mathrm{M}^{-1}$ in tap and river water samples. Nanotubes have also been incorporated into MIP layers with nanomolar limits also being reached using $\mathrm{TiO}_{2}$ nanotubes ${ }^{108}$ and even picomolar levels being obtained using vinylated MWCNT. ${ }^{109}$ In these examples, the MIP layer is used to increase the selectivity of the sensor, while the role of the nanotubes is to increase sensitivity.

Heavy metals are also of considerable interest for environmental monitoring with a number of methodologies being undertaken to detect mercury, ${ }^{110}$ arsenic, ${ }^{111}$ cadmium, ${ }^{112}$ lead, ${ }^{113}$ chromium, ${ }^{114}$ and copper. ${ }^{115}$ Graphene modified electrodes have been combined with gold nanoparticles to create
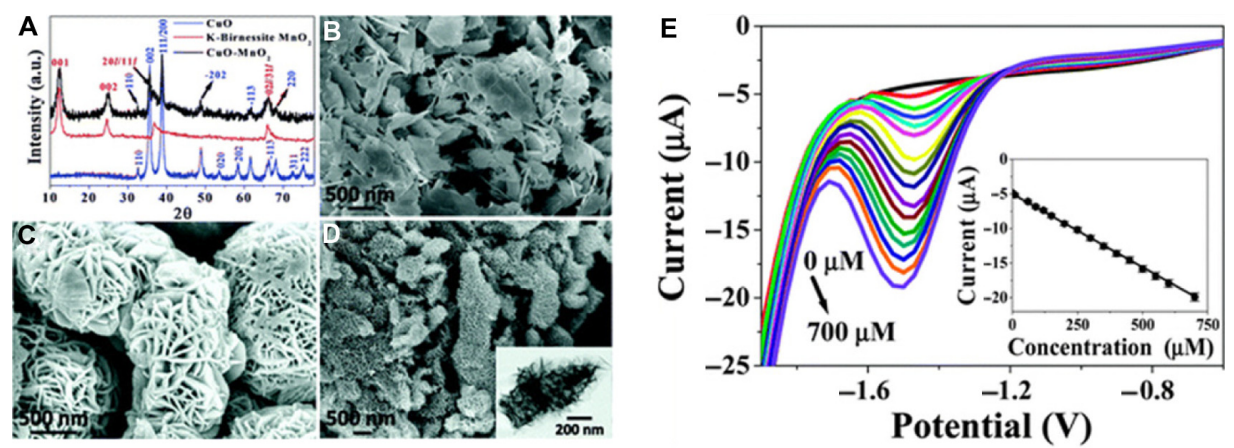

Figure 4 Structural information and images of modified electrodes and corresponding lindane calibration data.

Notes: (A) XRD patterns of materials synthesized in this study. SEM images of $\mathrm{CuO}$ (B), $\mathrm{MnO}_{2}$ (C), and CuO-MnO, (D); the inset shows the corresponding TEM image of $\mathrm{CuO}-\mathrm{MnO}_{2}$. (E) DPVs of lindane at varying concentrations at the $\mathrm{CuO}-\mathrm{MnO}_{2}$ modified electrode using $0.05 \mathrm{M}$ TBAB solution in 60 [thin space (I/6-em)]: [thin space $(1 / 6-e m)] 40$ methanol-water $(20 \mathrm{~mL})$. The inset shows the calibration plot. DPV parameters were selected as: peak height $=50 \mathrm{mV} ;$ peak width =200 ms; peak period $=400 \mathrm{~ms}$; increment $=20 \mathrm{mV}$; pre- and post-pulse width $=3 \mathrm{~ms}$. Adapted from Anu Prathap MU, Sun SN, Wei C, Xu ZJ. A novel non-enzymatic lindane sensor based on CuO-MnO 2 hierarchical nano-microstructures for enhanced sensitivity. Chem Commun (Camb). 2015;5I (21):4376-4379. ${ }^{106}$ With permission from The Royal Society of Chemistry. Abbreviations: XRD, X-ray powder diffraction; TEM, transmission electron microscope; SEM, scanning electron microscopy; DPV, differential pulse voltammetry; TBAB, tetra-n-butylammonium bromide. 
a DNA based mercury sensor with a detection limit of 0.001 $\mathrm{aM}$ (Enviornmental Protection Agency limit $=10 \mathrm{nM}) .{ }^{116}$ The incorporation of graphene improved the electrical characteristics of the electrode surface while a suitable covering of gold nanoparticles aided in the immobilization of DNA. The sensor was found to be largely unaffected when tested for selectivity against 14 other possible interfering ions and was successfully able to detect spiked mercury levels in landfill leachate, tap water, and river water with the results verified using atomic fluorescence spectrometry.

Pre-concentration methods are often used to achieve the low detection limits required for environmental analysis. Banerjee et al have utilized magnetic nanoshells as a novel means for the pre-concentration of uranium. ${ }^{117}$ First, gold nanoshells were synthesized with a magnetic $\mathrm{Fe}_{3} \mathrm{O}_{4}$ core and modified with $t$-butylphenyl- $N, N$-di-isobutyl carbamoylmethylphosphine oxide, a known extraction agent for uranium. The modified nanoshells collected uranium from solution before the insertion of a working electrode which comprised of a gold coated neodymium magnet. The uranium concentration was then determined using SWV in a range of 10-140 ppb with the carbamoylmethylphosphine oxide selectivity minimizing the effect of interfering $\mathrm{Cu}^{2+}$ and $\mathrm{Zn}^{2+}$ ions. Recently, more exhaustive reviews have been written focusing solely on the use of nanomaterials and nanostructuring for the detection of heavy metal ions ${ }^{118,119}$

\section{Food safety}

While the aforementioned detection of heavy metals in the environment is critical for their eventual removal and land remediation, it is still an on-going process. As such, their detection in food products is also an immediate concern. Afkhami et al have utilized nano-silica as a means of simultaneously detecting trace levels of cadmium, copper, and mercury in a range of water and food samples. ${ }^{120}$ Nanosilica was chosen over other nanomaterials because of its high specific surface area and its potential for high diffusion rates due to its three-dimensional structure. A Schiff base (BTPP) which could form complexes with targeted heavy metal ions was synthesized and used to easily modify the nano-silica due to an abundance of silanol groups located on the particles' internal surface allowing it to operate as an effective sorbent for heavy metals in aqueous media. These modified nano-silica particles were then incorporated into a carbon paste electrode. Once the electrode had been characterized and the optimal detection procedure using square wave anodic stripping voltammetry had been determined, an LOD of $0.05 \mathrm{ng} \mathrm{mL}^{-1}$ was achieved which was significantly lower than a majority of alternative methods referenced by the authors. The method was also applied to real world samples of tap water, Persian Gulf water, tobacco, fish and shrimp tissues, human hair, and rice samples with recovery percentages of between $96.9 \%$ and $104.5 \%$ for samples spiked with $20 \mathrm{ng} \mathrm{mL} \mathrm{mL}^{-1}$. These spiked levels and the base levels were successfully determined with the modified electrode and the results validated using inductively coupled plasma optical emission spectrometry (ICP-OES). The selectivity afforded by the BTPP remained robust with deviations below $5 \%$ found for $500 \mathrm{ng} \mathrm{mL}^{-1}$ of each heavy metal of interest when challenged with 10,000 ng mL ${ }^{-1}$ of $\mathrm{Ca}^{2+}, \mathrm{Co}^{2+}, \mathrm{Cr}^{3+}, \mathrm{Cr}(\mathrm{VI})$, $\mathrm{Al}^{3+}, \mathrm{Fe}^{3+}, \mathrm{Pb}^{2+}, \mathrm{Mn}^{2+}, \mathrm{Ni}^{2+}, \mathrm{Zn}^{2+}, \mathrm{Sr}^{2+}, \mathrm{Mg}^{2+}, \mathrm{Li}^{+}, \mathrm{Na}^{+}, \mathrm{SO}_{4}^{2-}$, $\mathrm{Cl}^{-}, \mathrm{NO}_{3}^{2-}, \mathrm{NO}_{2}^{-}, \mathrm{S}^{2-}$ and $\mathrm{ClO}_{4}^{-}$.

Carbon paste electrodes have also been combined with MWCNT for the measurement of $\mathrm{Cu}$ (II) in cornflakes and milk powder. ${ }^{121}$ The MWCNT carbon paste electrode was modified with a zinc layered hydroxide-2(3-chlorophenoxy) propionate nanocomposite and exhibited an LOD of $1 \times 10^{-10} \mathrm{M}$ that allowed for the quantification of $0.214 \mu \mathrm{g} / \mathrm{g}$ of $\mathrm{Cu}$ (II) in cornflakes (confirmed by ICP-OES). While the addition of MWCNT often improves the sensitivity and selectivity of a sensor, in this case the sensor was unresponsive to $\mathrm{Cu}(\mathrm{II})$. Upon the incorporation of the zinc layered nanocomposite, a quasi-reversible peak was observed. This can be attributed to the ion exchange and absorption capabilities of the nanocomposite. This showed significant improvement in detection limits when compared to other modified carbon paste electrodes while eliminating the need for a pre-concentration step which many of them required.

Milk and other dairy based products are highly consumed worldwide, with particularly high levels of consumption amongst young children. ${ }^{122}$ This large market has resulted in the development of a large variety of electrochemical sensors to assess milk quality for possible contaminants, including melamine, ${ }^{123,124}$ antibiotics, ${ }^{59,125}$ bisphenol A (from packaging contamination), ${ }^{126}$ DNA bases, ${ }^{127}$ and hydrogen peroxide. ${ }^{122,128,129}$ Hydrogen peroxide has been used as a means of artificially preserving milk $\mathrm{k}^{130}$ and due to the possibility of adverse health effects from over exposure, the US Food and Drug Administration has limited its acceptable concentration to $80 \mathrm{ppm} .{ }^{131}$ Eggshell membranes (ESMs) have been used as a platform for supporting graphene oxide (GO) for hydrogen peroxide sensitive electrodes. ${ }^{132}$ ESM offers an attractive support because of its excellent waterpermeability, biocompatibility, nontoxicity, cheapness, and stability but suffers from poor conductivity which is essential for the efficiency of electrochemical applications. 
ESM was modified with GO to overcome this limitation and the ESM-GO bioplatform was then immobilized on a ceramic carbon electrode. The response of the resulting modified electrode was further improved by the dip-coating of PB nanoparticles on the surface which is known to increase the catalytic activity of electrodes toward the electrochemical reduction of hydrogen peroxide. An LOD of $31 \mathrm{nM}$ was achieved which showed significant improvement over other graphene based electrodes for peroxide detection. ${ }^{133-137}$ The incorporation of $\mathrm{PB}$ is common in many peroxide sensors as it has well known electrocatalytic properties for peroxide redox reactions. This is attributed to the unique zeolite structure of PB which allows molecules with low molecular weight and scale to penetrate into the crystal resulting in improved electrocatalysis. Although commonly used for decoration of macro electrodes, $\mathrm{PB}$ is unsuitable for use with electrodes fabricated using photolithographic techniques as it is often electrodeposited from acidic solutions which can attack the electrodes' adhesion layer and cause delamination.

The versatility of electrochemical nanosensors is further evident in the food sector with an array of electrode types being used to detect compounds like sulfite in sugar, grapes, wine and water, ${ }^{138}$ staphylococcal enterotoxin B (a possible source of food poisoning), ${ }^{139}$ aflatoxin, ${ }^{12}$ durabolin, ${ }^{11}$ and animal growth stimulants ${ }^{140}$ to name a few. ${ }^{141}$

\section{Outlook and conclusion}

As can be seen from the examples detailed earlier, nanoelectrochemistry offers a viable alternative to traditional laboratory techniques currently used for the detection of a range of analytes across a number of fields. When compared to existing methods (high-performance liquid chromatography, ICP-OES, gas chromatography-mass spectrometry), electrochemistry has the potential to offer faster and more portable analysis at highly reduced equipment costs with methods that can be preprogramed to eliminate the need for highly trained laboratory staff. While the use of nanomaterials and nanoelectrodes can provide an enhanced sensor response due to a number of factors, eg, increased electrocatalytic activity, increased charge transfer, increased surface area, and radial diffusion, there are also a number of drawbacks inhibiting the widespread uptake on a commercial level. In relation to nanomaterials, the long-term health and safety implications on humans and in the environment are largely unknown. While bulk materials such as gold may be inert and biocompatible, it is possible that nanometer sized particles may be toxic due to their size allowing for translocation within the body. In addition to this, the larger surface area can increase the likelihood of chemical reactions which may cause the formation of harmful free radicals. It is also unclear whether some of the more novel nanomaterials could be produced on a commercially sustainable scale while maintaining a satisfactory size distribution. Another scalability concern would be the modification of electrodes with the desired nanomaterial. While modification may be facile on a laboratory scale, it is unlikely to transfer easily to a larger scale.

In this regard, nanoelectrodes can be considered an attractive alternative. While some nanoelectrodes, such as those fabricated using laser pulling technology may be fragile, more robust electrodes have been fabricated using photolithographic techniques. As these techniques are being routinely used within the microelectronics industry, it is clear that these electrodes may be fabricated on a large scale. Currently, standard photolithography allows for the fabrication of structures of $\sim 500-700 \mathrm{~nm}$ in width with other methods being required for smaller scale electrodes. E-beam lithography is one such method, but while the size reduction may offer favorable sensor performance it also increases the cost and time required for sensor fabrication.

Extreme ultraviolet (EUV) lithography combined with immersion lenses has the potential to provide a faster and cheaper alternative but as of yet still faces a number of challenges preventing its widespread uptake. ${ }^{142}$ First, further development of EUV power sources is required. Current available lasers are of low power and thus longer processing times are needed. Another challenge remaining for EUV lithography is the need for the development of a suitably sensitive resist so that the finest resolution can be realized. Also, in order to ensure devices with a satisfactory reproducibility are fabricated a highly qualified defect free photomask is necessary. Fabricating such a mask with an acceptably low defect count can be challenging. The immersion aspect of this technique can also be problematic. Physical processing errors such as air bubbles in the liquid can be detrimental to final devices or ionization of the water by the EUV may cause damage to the photoresist.

Nanoimprint lithography (NIL) could offer low cost nanoscale devices with a high throughput once a number of difficulties are overcome. ${ }^{143,144}$ For NIL, a suitable template must first be fabricated which can prove difficult at the nanoscale. E-beam lithography does offer the ability to produce these templates and, as they can be reused hundreds, or even thousands of times (depending on the substrate), the cost and time consumption would no longer be a prohibitive factor. Once a suitable template has been fabricated, issues arise due to the contact nature of the technique. This increases the possibility 
of the fine structures of the template being damaged during fabrication which would affect the reproducibility of sensor fabrication. Processing related problems also exist with NIL as the removal of residual resist can be difficult and if a thermal cure is used this can result in pattern distortion.

Nanometer scale bands can be fabricated using an etching process but these bands are recessed within wells which limits diffusion of analytes to the electrode surface. Another shortcoming of nanoelectrodes is the current range that they operate within. Measured currents are frequently in the nanoamp or picoamp range. As a result, a Faraday cage is often necessary to reduce or eliminate background noise contributions.

This review has highlighted recent advances in the application of nanoelectrochemistry for the development of analytical sensors. As the demand for smaller, faster, cheaper, and ultrasensitive qualification and quantification of samples rapidly increases, these methods provide a viable path toward the next generation of electrochemical sensors. Further advances in the synthesis of nanomaterials and the fabrication of discrete nanoelectrodes has the potential to benefit society in a broad scope of areas as discussed earlier, with the prospective for real-time point of care detection of analytes slowly being realized. A major challenge remaining for the commercial development of such applications is the requirement for a reproducible, low cost production process for nanomaterial based devices on an economically beneficial scale while maintaining the accuracy achieved within a laboratory environment.

\section{Acknowledgments}

This publication has emanated from research supported in part by a research grant from Science Foundation Ireland (SFI), USIreland Programme (SFI12/US/I2476), and the Department of Agriculture Food and the Marine - Flukeless (13S405).

\section{Disclosure}

The authors are not aware of any affiliations, memberships, funding, or financial holdings that might be perceived as affecting the objectivity of this review. The authors report no conflicts of interest in this work.

\section{References}

1. Wang XQ, Mujumdar AS. Heat transfer characteristics of nanofluids: a review. International Journal of Thermal Sciences. 2007;46(1):1-19.

2. Hossain MN, Justice J, Lovera P, McCarthy B, O'Riordan A, Corbett B. High aspect ratio nano-fabrication of photonic crystal structures on glass wafers using chrome as hard mask. Nanotechnology. 2014; 25(35):355301.
3. Rocha-Santos TAP. Sensors and biosensors based on magnetic nanoparticles. TrAC Trends in Analytical Chemistry. 2014;62: 28-36.

4. Xu PA, Zeng GM, Huang DL, et al. Use of iron oxide nanomaterials in wastewater treatment: A review. Sci Total Environ. 2012;424: $1-10$.

5. Lovera P, Jones D, Corbett B, O'Riordan A. Polarization tunable transmission through plasmonic arrays of elliptical nanopores. Opt Express. 2012;20(23):25325-25332.

6. Lovera P, Creedon N, Alatawi H, et al. Low-cost silver capped polystyrene nanotube arrays as super-hydrophobic substrates for SERS applications. Nanotechnology. 2014;25(17):175502.

7. Pal J, Pal T. Faceted metal and metal oxide nanoparticles: design, fabrication and catalysis. Nanoscale. 2015;7(34):14159-14190.

8. Guo S, Wang E. Noble metal nanomaterials: Controllable synthesis and application in fuel cells and analytical sensors. Nano Today. 2011; 6(3):240-264

9. Sharp D, Burkitt R. Carbon materials for analytical electrochemistry: printed carbon materials and composites. Materials Technology. 2015;30(B3):B155-B162.

10. Su S, Wei X, Guo Y, et al. A Silicon Nanowire-Based Electrochemical Sensor with High Sensitivity and Electrocatalytic Activity. Particle and Particle Systems Characterization. 2013;30(4):326-331.

11. Wan FW, Yu JH, Yang P, Ge SG, Yan M. An electrochemiluminescence sensor for determination of durabolin based on CdTe QD films by layer-by-layer self-assembly. Anal Bioanal Chem. 2011;400(3):807-814.

12. Kalita P, Singh J, Singh MK, Solanki PR, Sumana G, Malhotra BD. Ring like self assembled Ni nanoparticles based biosensor for food toxin detection. Applied Physics Letters. 2012;100(9).

13. Lin Z, Ji L, Medford AJ, Shi Q, Krause WE, Zhang X. Electrocatalytic interaction of nano-engineered palladium on carbon nanofibers with hydrogen peroxide and beta-NADH. Journal of Solid State Electrochemistry. 2011;15(6):1287-1294.

14. Sahoo P, Suresh S, Dhara S, Saini G, Rangarajan S, Tyagi AK. Direct label free ultrasensitive impedimetric DNA biosensor using dendrimer functionalized $\mathrm{GaN}$ nanowires. Biosens Bioelectron. 2013;44:164-170.

15. Salavati H, Fazilati M, Behrooznam R. Study on Electrochemical Behavior of Horseridash peroxidase Enzyme by $\mathrm{MgO}$ Nanoparticles Modified Electrode to Identify Hydrogen peroxide. International Journal of Electrochemical Science. 2014;9(12):7460-7470.

16. Tzamtzis N, Psychoyios VN, Nikoleli GP, et al. Flow Potentiometric Injection Analysis of Uric Acid Using Lipid Stabilized Films with Incorporated Uricase on ZnO Nanowires. Electroanalysis. 2012; 24(8):1719-1725.

17. Willander M, Khun K, Ibupoto $\mathrm{ZH}$. ZnO based potentiometric and amperometric nanosensors. J Nanosci Nanotechnol. 2014; 14(9):6497-6508.

18. Yu Y, Gao Y, Hu K, et al. Electrochemistry and Electrocatalysis at Single Gold Nanoparticles Attached to Carbon Nanoelectrodes. ChemElectroChem. 2015;2(1):58-63.

19. El-Sayed HA, Campbell HB, Birss VI. Electrochemical applications of a Au nanoparticle array fabricated using highly ordered dimpled $\mathrm{Ta}$ templates. Electrochimica Acta. 2013;112:845-852.

20. Arrigan DW. Nanoelectrodes, nanoelectrode arrays and their applications. Analyst. 2004;129(12):1157-1165.

21. Wahl A, Barry S, Dawson K, MacHale J, Quinn AJ, O'Riordan A. Electroanalysis at Ultramicro and Nanoscale Electrodes: A Comparative Study. Journal of the Electrochemical Society. 2014;161(2): B3055-B3060.

22. Dawson K, Baudequin M, Sassiat N, Quinn AJ, O'Riordan A. Electroanalysis at discrete arrays of gold nanowire electrodes. Electrochimica Acta. 2012;101:169-176.

23. Dawson K, O'Riordan A. Electroanalysis at the Nanoscale. Annual Review of Analytical Chemistry. 2014;7:163-181. 
24. Liu YZ, Yao QQ, Zhang XM, Li MN, Zhu AW, Shi GY. Development of gold nanoparticle-sheathed glass capillary nanoelectrodes for sensitive detection of cerebral dopamine. Biosens Bioelectron. 2015;63: 262-268.

25. Hu KK, Gao Y, Wang YX, et al. Platinized carbon nanoelectrodes as potentiometric and amperometric SECM probes. Journal of Solid State Electrochemistry. 2013;17(12):2971-2977.

26. Takahashi Y, Shevchuk AI, Novak P, et al. Multifunctional Nanoprobes for Nanoscale Chemical Imaging and Localized Chemica Delivery at Surfaces and Interfaces. Angewandte Chemie. 2011; 50(41):9638-9642.

27. Danis L, Snowden ME, Tefashe UM, Heinemann CN, Mauzeroll J. Development of Nano-Disc electrodes for Application as Shear Force Sensitive Electrochemical Probes. Electrochimica Acta. 2014;136: 121-129.

28. Cox JT, Zhang B. Nanoelectrodes: Recent Advances and New Directions. In: Cooks RG, Yeung ES, editors. Annual Review of Analytical Chemistry, Vol 5. Palo Alto: Annual Reviews; 2012:253-272.

29. Oja SM, Wood M, Zhang B. Nanoscale Electrochemistry. Anal Chem. 2013;85(2):473-486.

30. Bottari F, Oliveri P, Ugo P. Electrochemical immunosensor based on ensemble of nanoelectrodes for immunoglobulin IgY detection Application to identify hen's egg yolk in tempera paintings. Biosens Bioelectron. 2014;52:403-410.

31. McPartlin DA, O'Kennedy RJ. Point-of-care diagnostics, a major opportunity for change in traditional diagnostic approaches: potential and limitations. Expert Rev Mol Diagn. 2014;14(8):979-998.

32. Jiao L, Lu G, Zhang C, et al. Aptamer and graphene-based electrochemical biosensor for dopamine determination with high sensitivity and selectivity. Micro and Nano Letters. 2013;8(12):903-905.

33. Zhao Y, Li SH, Chu J, et al. A nano-sized Au electrode fabricated using lithographic technology for electrochemical detection of dopamine. Biosens Bioelectron. 2012;35(1):115-122.

34. Ma C, Contento NM, Gibson LR 2nd, Bohn PW. Recessed ringdisk nanoelectrode arrays integrated in nanofluidic structures for selective electrochemical detection. Anal Chem. 2013;85(20): 9882-9888.

35. Saghatforoush L, Hasanzadeh M, Shadjou N. Polystyrene-graphene oxide modified glassy carbon electrode as a new class of polymeric nanosensors for electrochemical determination of histamine. Chinese Chemical Letters. 2014;25(4):655-658.

36. Soleymani L, Fang Z, Lam B, et al. Hierarchical nanotextured microelectrodes overcome the molecular transport barrier to achieve rapid, direct bacterial detection. ACS Nano. 2011;5(4):3360-3366.

37. Mohammadi A, Moghaddam AB, Eilkhanizadeh K, Alikhani E, Mozaffari S, Yavari T. Electro-oxidation and simultaneous determination of amlodipine and atorvastatin in commercial tablets using carbon nanotube modified electrode. Micro and Nano Letters. 2013;8(8): 413-417.

38. Li Y, Liu Y, Liu J, et al. Molecularly imprinted polymer decorated nanoporous gold for highly selective and sensitive electrochemical sensors. Scientific Reports. 2015;5:7699.

39. Putzbach W, Ronkainen NJ. Immobilization Techniques in the Fabrication of Nanomaterial-Based Electrochemical Biosensors: A Review. Sensors. 2013;13(4):4811-4840.

40. Dawson K, Baudequin M, O'Riordan A. Single on-chip gold nanowires for electrochemical biosensing of glucose. Analyst. 2011; 136(21):4507-4513.

41. Kratz A, Ferraro M, Sluss PM, Lewandrowski KB. Laboratory reference value. $N$ Engl J Med. 2004;351(15):1548-1563.

42. Soares MS, Batista-Filho MM, Pimentel MJ, Passos IA, ChimenosKuestner E. Determination of salivary glucose in healthy adults. Med Oral Patol Oral Cir Bucal. 2009;14(10):e510-e513.

43. Di Gioia ML, Leggio A, Le Pera A, et al. Quantitative analysis of human salivary glucose by gas chromatography-mass spectrometry. $J$ Chromatogr B Analyt Technol Biomed Life Sci. 2004;801(2):355-358.
44. Barrett C, Dawson K, O'Mahony C, O'Riordan A. Development of Low Cost Rapid Fabrication of Sharp Polymer Microneedles for In Vivo Glucose Biosensing Applications. ECS Journal of Solid State Science and Technology. 2015;4(10):S3053-S3058.

45. Dawson K, Wahl A, Murphy R, O'Riordan A. Electroanalysis at Single Gold Nanowire Electrodes. Journal of Physical Chemistry C. 2012; 116(27): 14665-14673.

46. Carrara S, Bolomey L, Boero C, et al. Single-Metabolite Bio-NanoSensors and System for Remote Monitoring in Animal Models. IEEE Sensors Journal. 2011:716-719.

47. Wang HH, Bu Y, Dai WL, Li K, Wang HD, Zuo X. Well-dispersed cobalt phthalocyanine nanorods on graphene for the electrochemical detection of hydrogen peroxide and glucose sensing. Sensors and Actuators B: Chemical. 2015;216:298-306.

48. Tian K, Alex S, Siegel G, Tiwari A. Enzymatic glucose sensor based on Au nanoparticle and plant-like $\mathrm{ZnO}$ film modified electrode. Mater Sci Eng C Mater Biol Appl. 2015;46:548-552.

49. Clausmeyer J, Actis P, Cordoba AL, Korchev Y, Schuhmann W. Nanosensors for the detection of hydrogen peroxide. Electrochemistry Communications. 2014;40:28-30.

50. Dawson K, Strutwolf J, Rodgers KP, et al. Single Nanoskived Nanowires for Electrochemical Applications. Analytical Chemistry. 2011;83(14):5535-5540.

51. Kim S, Na J, Lee SK, et al. Geometrical effects of nanowire electrodes for amperometric enzyme biosensors. Sensors and Actuators B: Chemical. 2013;183:222-229.

52. Rafipour R, Kashanian S, Abasi Tarighat F. Sensitive electrochemical biosensing of $\mathrm{H} 2 \mathrm{O} 2$ based on cobalt nanoparticles synthesised in iron storage protein molecules, ferritin. IET Nanobiotechnol. 2014; 8(4):196-200.

53. Cao GS, Wang P, Li X, Wang Y, Wang G, Li J. Hydrogen peroxide electrochemical sensor based on $\mathrm{Fe} 3 \mathrm{O} 4$ nanoparticles. Micro and Nano Letters. 2014;9(1):16-18.

54. Khan AA, Alzohairy MA. Recent advances and applications of immobilized enzyme technologies: a review. Res J Biol Sci. 2010;5(8): $565-575$.

55. Li G, Wang X, Liu L, et al. Controllable synthesis of 3D Ni(OH)(2) and $\mathrm{NiO}$ nanowalls on various substrates for high-performance nanosensors. Small. 2015;11(6):731-739.

56. Wang G, Zhu Y, Nan H, Ma W, Zhang X. Study on porous Cu-based enzyme-free glucose electrochemical sensor with different entrapping agents. Micro and Nano Letters. 2013;8(8):395-399.

57. Ricci F, Adornetto G, Palleschi G. A review of experimental aspects of electrochemical immunosensors. Electrochimica Acta. 2012;84 74-83.

58. Singh KV, Whited AM, Ragineni Y, Barrett TW, King J, Solanki R. 3D nanogap interdigitated electrode array biosensors. Analytical and Bioanalytical Chemistry. 2010;397(4):1493-1502.

59. Li H, Xu B, Wang DQ, et al. Immunosensor for trace penicillin G detection in milk based on supported bilayer lipid membrane modified with gold nanoparticles. J Biotechnol. 2015;203:97-103.

60. Liu GZ, Liu JQ, Davis TP, Gooding JJ. Electrochemical impedance immunosensor based on gold nanoparticles and aryl diazonium salt functionalized gold electrodes for the detection of antibody. Biosens Bioelectron. 2011;26(8):3660-3665.

61. Yang ZJ, Jian ZQ, Chen X, et al. Electrochemical impedance immunosensor for sub-picogram level detection of bovine interferon gamma based on cylinder-shaped TiO2 nanorods. Biosens Bioelectron. 2015;63:190-195.

62. Chang YT, Huang JH, Tu MC, Chang P, Yew TR. Flexible direct-growth CNT biosensors. Biosens Bioelectron. 2013;41:898-902.

63. Bonanni A, Loo AH, Pumera M. Graphene for impedimetric biosensing. TrAC Trends in Analytical Chemistry. 2012;37:12-21.

64. Hu CY, Yang DP, Xu K, et al. Ag@BSA Core/Shell Microspheres As an Electrochemical Interface for Sensitive Detection of Urinary RetinalBinding Protein. Analytical Chemistry. 2012;84(23):10324-10331. 
65. Jin B, Wang P, Mao HJ, et al. Multi-nanomaterial electrochemical biosensor based on label-free graphene for detecting cancer biomarkers. Biosens Bioelectron. 2014;55:464-469.

66. Dong F, Luo R, Chen H, Zhang W, Ding SJ. Amperometric Immunosensor Based on Carbon Nanotubes/Chitosan Film Modified Electrodes for Detection of Human Leptin. International Journal of Electrochemical Science. 2014;9(12):6924-6935.

67. Galik M, O’Mahony AM, Wang J. Cyclic and Square-Wave Voltammetric Signatures of Nitro-Containing Explosives. Electroanalysis. 2011;23(5):1193-1204.

68. Wen YL, Pei H, Wan Y, et al. DNA nanostructure-decorated surfaces for enhanced aptamer-target binding and electrochemical cocaine sensors. Anal Chem. 2011;83(19):7418-7423.

69. Ribeiro WF, da Costa DJE, Lourenco AS, et al. Electrochemical study of ricin at glassy carbon electrode. Analyst. 2013;138(16): 4565-4573.

70. Periyakaruppan A, Arumugam PU, Meyyappan M, Koehne JE. Detection of ricin using a carbon nanofiber based biosensor. Biosens Bioelectron. 2011;28(1):428-433.

71. Chua CK, Pumera M, Rulisek L. Reduction Pathways of 2,4, 6-Trinitrotoluene: An Electrochemical and Theoretical Study. Journal of Physical Chemistry C. 2012;116(6):4243-4251.

72. Barry S, Dawson K, Correa E, Goodacre R, O'Riordan A. Highly sensitive detection of nitroaromatic explosives at discrete nanowire arrays. Faraday Discuss. 2013;164:283-293.

73. Dawson K, Wahl A, Barry S, et al. Fully integrated on-chip nano-electrochemical devices for electroanalytical applications. Electrochimica Acta. 2014;115:239-246.

74. Fierke MA, Olson EJ, Buehlmann P, Stein A. Receptor-based detection of 2,4-dinitrotoluene using modified three-dimensionally ordered macroporous carbon electrodes. ACS Appl Mater Interfaces. 2012; 4(9):4731-4739.

75. O’Mahony AM, Valdes-Ramirez G, Windmiller JR, Samek IA, Wang J. Orthogonal Detection of Nitroaromatic Explosives via Direct Voltammetry Coupled to Enzyme-Mediated Biocatalysis. Electroanalysis. 2012;24(9):1811-1816.

76. Chen W, Wang Y, Brueckner C, Li CM, Lei Y. Poly[meso-tetrakis (2-thienyl)porphyrin] for the sensitive electrochemical detection of explosives. Sensors and Actuators B: Chemical. 2010;147(1): 191-197.

77. Guo CX, Lei Y, Li CM. Porphyrin Functionalized Graphene for Sensitive Electrochemical Detection of Ultratrace Explosives. Electroanalysis. 2011;23(4):885-893.

78. Guo S, Wen D, Zhai Y, Dong S, Wang E. Ionic liquid-graphene hybrid nanosheets as an enhanced material for electrochemical determination of trinitrotoluene. Biosens Bioelectron. 2011;26(8):3475-3481.

79. Wang L, Zhang XH, Xiong HY, Wang SF. A novel nitromethane biosensor based on biocompatible conductive redox graphene-chitosan/ hemoglobin/graphene/room temperature ionic liquid matrix. Biosens Bioelectron. 2010;26(3):991-995.

80. Shamsipur M, Tabrizi MA, Mahkam M, Aboudi J. A High Sensitive TNT Sensor Based on Electrochemically Reduced Graphene Oxide-Poly(amidoamine) Modified Electrode. Electroanalysis. 2015; 27(6):1466-1472.

81. Chen TW, Sheng ZH, Wang K, Wang FB, Xia XH. Determination of explosives using electrochemically reduced graphene. Chem Asian J. 2011;6(5):1210-1216.

82. Rameshkumar P, Ramaraj R. Electroanalysis of nitrobenzene derivatives and nitrite ions using silver nanoparticles deposited silica spheres modified electrode. Journal of Electroanalytical Chemistry. 2014;731: 72-77.

83. Riedel J, Berthold M, Guth U. Electrochemical determination of dissolved nitrogen-containing explosives. Electrochimica Acta. 2014;128: 85-90.

84. Bozic RG, West AC. Electrochemical detection of 14 common munitions constituents. Journal of Applied Electrochemistry. 2014; 44(2):293-300.
85. Jimenez-Perez R, Baron M, Elie L, Rodriguez JG. Design of a virtual sensor data array for the analysis of RDX, HMX and DMNB using metal-doped screen printed electrodes and chemometric analysis. International Journal of Electrochemical Science. 2013;8(3): 3279-3289.

86. Guo Z, Florea A, Cristea C, et al. 1,3,5-Trinitrotoluene detection by a molecularly imprinted polymer sensor based on electropolymerization of a microporous-metal-organic framework. Sensors and Actuators B: Chemical. 2015;207:960-966

87. United Nations office on Drugs and Crime. World Drug Report 2014. United Nations office on Drugs and Crime; 2014. Available from: https://www.unodc.org/documents/wdr2014/World_Drug_ Report_2014_web.pdf. Accessed November 30, 2015.

88. Mokhtarzadeh A, Dolatabadi JE, Abnous K, de la Guardia M, Ramezani M. Nanomaterial-based cocaine aptasensors. Biosens Bioelectron. 2015;68:95-106.

89. Roushani M, Shahdost-fard F. A novel ultrasensitive aptasensor based on silver nanoparticles measured via enhanced voltammetric response of electrochemical reduction of riboflavin as redox probe for cocaine detection. Sensors and Actuators B: Chemical. 2015;207:764-771.

90. Das J, Cederquist KB, Zaragoza AA, Lee PE, Sargent EH, Kelley SO. An ultrasensitive universal detector based on neutralizer displacement. Nat Chem. 2012;4(8):642-648.

91. Atta NF, Galal A, Hassan SH. Electrochemical Sensor for Morphine Based on Gold Nanoparticles/ Ferrocene Carboxylic Acid/Poly (3,4-Ethylene-Dioxythiophene) Composite. International Journal of Electrochemical Science. 2015;10(3):2265-2280.

92. Ensafi AA, Rezaei B, Krimi-Maleh H. An ionic liquid-type multiwall carbon nanotubes paste electrode for electrochemical investigation and determination of morphine. Ionics. 2011;17(7):659-668.

93. Aragay G, Pino F, Merkoci A. Nanomaterials for Sensing and Destroying Pesticides. Chem Rev. 2012;112(10):5317-5338.

94. Li M, Li YT, Li DW, Long YT. Recent developments and applications of screen-printed electrodes in environmental assays-A review. Anal Chim Acta. 2012;734:31-44.

95. Oakes DJ, Webster WS, Brown-Woodman PDC, Ritchie HE. A study of the potential for a herbicide formulation containing 2,4-D and picloram to cause male-mediated developmental toxicity in rats. Toxicol Sci. 2002;68(1):200-206.

96. Isbister GK, Mills K, Friberg LE, et al. Human methyl parathion poisoning. Clinical Toxicology. 2007;45(8):956-960.

97. Chen S, Huang J, Du D, et al. Methyl parathion hydrolase based nanocomposite biosensors for highly sensitive and selective determination of methyl parathion. Biosens Bioelectron. 2011;26(11):4320-4325.

98. Zhu W, Liu W, Li T, et al. Facile green synthesis of graphene-Au nanorod nanoassembly for online extraction and sensitive stripping analysis of methyl parathion. Electrochimica Acta. 2014;146:419-428.

99. Zhao H, Ji X, Wang B, et al. An ultra-sensitive acetylcholinesterase biosensor based on reduced graphene oxide-Au nanoparticles-betacyclodextrin/Prussian blue-chitosan nanocomposites for organophosphorus pesticides detection. Biosens Bioelectron. 2015;65C:23-30.

100. Musameh M, Notivoli MR, Hickey M, et al. Carbon nanotube webs: a novel material for sensor applications. Adv Mater. 2011;23(7): 906-110.

101. Fu XC, Zhang J, Tao YY, Wu J, Xie CG, Kong LT. Three-dimensional mono-6-thio-beta-cyclodextrin covalently functionalized gold nanoparticle/single-wall carbon nanotube hybrids for highly sensitive and selective electrochemical determination of methyl parathion. Electrochimica Acta. 2015;153:12-18.

102. Yao YY, Zhang L, Xu JK, Wang XQ, Duan XM, Wen YP. Rapid and sensitive stripping voltammetric analysis of methyl parathion in vegetable samples at carboxylic acid-functionalized SWCNTsbeta-cyclodextrin modified electrode. Journal of Electroanalytical Chemistry. 2014;713:1-8.

103. Wu S, Lan X, Cui L, et al. Application of graphene for preconcentration and highly sensitive stripping voltammetric analysis of organophosphate pesticide. Analytica Chimica Acta. 2011;699(2):170-176. 
104. Torres Padron ME, Sosa Ferrera Z, Santana Rodriguez JJ. Optimisation of solid-phase microextraction coupled to HPLC-UV for the determination of organochlorine pesticides and their metabolites in environmental liquid samples. Anal Bioanal Chem. 2006; 386(2):332-340.

105. Humphreys EH, Janssen S, Heil A, Hiatt P, Solomon G, Miller MD. Outcomes of the California ban on pharmaceutical lindane: Clinical and ecologic impacts. Environ Health Perspect. 2008;116(3):297-302.

106. Anu Prathap MU, Sun SN, Wei C, Xu ZJ. A novel non-enzymatic lindane sensor based on $\mathrm{CuO}-\mathrm{MnO} 2$ hierarchical nano-microstructures for enhanced sensitivity. Chem Commun (Camb). 2015;51(21): 4376-4379.

107. Kaur B, Srivastava R, Satpati B. Silver nanoparticle decorated polyaniline-zeolite nanocomposite material based non-enzymatic electrochemical sensor for nanomolar detection of lindane. RSC Advances. 2015;5(71):57657-57665.

108. Wang PP, Ge L, Li M, et al. Photoelectrochemical Sensor Based on Molecularly Imprinted Polymer-Coated TiO2 Nanotubes for Lindane Specific Recognition and Detection. Journal of Inorganic and Organometallic Polymyers and Materials. 2013;23(3): 703-711.

109. Anirudhan TS, Alexander S. Design and fabrication of molecularly imprinted polymer-based potentiometric sensor from the surface modified multiwalled carbon nanotube for the determination of lindane (gamma-hexachlorocyclohexane), an organochlorine pesticide. Biosens Bioelectron. 2015;64:586-593.

110. Lin YW, Huang CC, Chang HT. Gold nanoparticle probes for the detection of mercury, lead and copper ions. Analyst. 2011;136(5): 863-871.

111. Hung DQ, Nekrassova O, Compton RG. Analytical methods for inorganic arsenic in water: a review. Talanta. 2004;64(2):269-277.

112. Rose M, Knaggs M, Owen L, Baxter M. A review of analytical methods for lead, cadmium, mercury, arsenic and tin determination used in proficiency testing. Journal of Analalytical Atomic Spectrometry. 2001;16(9):1101-1106.

113. Kim HN, Ren WX, Kim JS, Yoon J. Fluorescent and colorimetric sensors for detection of lead, cadmium, and mercury ions. Chem Soc Rev. 2012;41(8):3210-3244.

114. Gomez V, Callao MP. Chromium determination and speciation since 2000. TrAC Trends in Analytical Chemistry. 2006;25(10) 1006-1015.

115. Baryla A, Laborde C, Montillet JL, Triantaphylides C, Chagvardieff P. Evaluation of lipid peroxidation as a toxicity bioassay for plants exposed to copper. Environ Pollut. 2000;109(1):131-135.

116. Zhang Y, Zeng GM, Tang L, et al. Electrochemical Sensor Based on Electrodeposited Graphene-Au Modified Electrode and NanoAu Carrier Amplified Signal Strategy for Attomolar Mercury Detection. Anal Chem. 2015;87(2):989-996.

117. Banerjee R, Katsenovich Y, Lagos L, et al. Functional magnetic nanoshells integrated nanosensor for trace analysis of environmental uranium contamination. Electrochimica Acta. 2010;55(27): 7897-7902.

118. Li M, Gou HL, Al-Ogaidi I, Wu NQ. Nanostructured Sensors for Detection of Heavy Metals: A Review. ACS Sustainable Chemistry and Engineering. 2013;1(7):713-723.

119. Gumpu MB, Sethuraman S, Krishnan UM, Rayappan JB. A review on detection of heavy metal ions in water - An electrochemical approach. Sensors and Actuators B: Chemical. 2015;213:515-533.

120. Afkhami A, Soltani-Felehgari F, Madrakian T, Ghaedi H, Rezaeivala M. Fabrication and application of a new modified electrochemical sensor using nano-silica and a newly synthesized Schiff base for simultaneous determination of $\mathrm{Cd} 2+, \mathrm{Cu} 2+$ and $\mathrm{Hg} 2+$ ions in water and some foodstuff samples. Anal Chim Acta. 2013;771:21-30.

121. Wardani NI, Isa IM, Hashim N, Ab Ghani S. Zinc layered hydroxide-2(3-chlorophenoxy)propionate modified multi-walled carbon nanotubes paste electrode for the determination of nano-molar levels copper(II). Sensors and Actuators B: Chemical. 2014;198:243-248.
122. Thandavan K, Gandhi S, Nesakumar N, Sethuraman S, Rayappan JB, Krishnan UM. Hydrogen peroxide biosensor utilizing a hybrid nanointerface of iron oxide nanoparticles and carbon nanotubes to assess the quality of milk. Sensors and Actuators B: Chemical. 2015;215: 166-173.

123. Cao H, Hu X, Hu C, Zhang Y, Jia N. A novel solid-state electrochemiluminescence sensor for melamine with Ru(bpy)(3) (2+)/mesoporous silica nanospheres/Nafion composite modified electrode. Biosens Bioelectron. 2013;41:911-915.

124. Zhou L, Huang J, Yang L, Li L, You T. Enhanced electrochemiluminescence based on Ru(bpy)(3)(2+)-doped silica nanoparticles and graphene composite for analysis of melamine in milk. Anal Chim Acta. 2014;824:57-63.

125. Conzuelo F, Ruiz-Valdepenas Montiel V, Campuzano S, et al. Rapid screening of multiple antibiotic residues in milk using disposable amperometric magnetosensors. Anal Chim Acta. 2014;820: 32-38.

126. Yi J, Tang S, Wang Z, et al. Electrochemical determination of bisphenol A based on PHD/MWCNTs modified glassy carbon electrode. International Journal of Environmental Analytical Chemistry. 2015; 95(2):158-174.

127. Ye XL, Du YL, Duan KY, Lu DB, Wang CM, Shi XZ. Fabrication of nano-ZnS coated PEDOT-reduced graphene oxide hybrids modified glassy carbon-rotating disk electrode and its application for simultaneous determination of adenine, guanine, and thymine. Sensors and Actuators B: Chemical. 2014;203:271-281.

128. Annamalai SK, Palani B, Pillai KC. Highly stable and redox active nano copper species stabilized functionalized-multiwalled carbon nanotube/chitosan modified electrode for efficient hydrogen peroxide detection. Colloids and Surfaces A: Physicochemical and Engineering Aspects. 2012;395:207-216.

129. Ensafi AA, Jafari-Asl M, Rezaei B. A novel enzyme-free amperometric sensor for hydrogen peroxide based on Nafion/exfoliated graphene oxide-Co3O4 nanocomposite. Talanta. 2013;103:322-329.

130. Singh P, Gandhi N. Milk Preservatives and Adulterants: Processing, Regulatory and Safety Issues. Food Reviews International. 2015;31(3): 236-261.

131. Chiu MH, Kumar AS, Sornambikai S, Chen PY, ShihY, Zen JM. Cosmetic Hydrogen Peroxide Detection Using Nano Bismuth Species Deposited Built-in Three-in-One Screen-Printed Silver Electrode. International Journal of Electrochemical Science. 2011;6(7):2352-2365.

132. Mohammad-Rezaei R, Razmi H, Dehgan-Reyhan S. Preparation of graphene oxide doped eggshell membrane bioplatform modified Prussian blue nanoparticles as a sensitive hydrogen peroxide sensor. Colloids Surf B Biointerfaces. 2014;118:188-193.

133. Jiang Y, Zhang X, Shan C, et al. Functionalization of graphene with electrodeposited Prussian blue towards amperometric sensing application. Talanta. 2011;85(1):76-81.

134. Yang JH, Myoung N, Hong HG. Facile and controllable synthesis of Prussian blue on chitosan-functionalized graphene nanosheets for the electrochemical detection of hydrogen peroxide. Electrochimica Acta. 2012;81:37-43.

135. Ye Y, Kong T, Yu X, Wu Y, Zhang K, Wang X. Enhanced nonenzymatic hydrogen peroxide sensing with reduced graphene oxide/ ferroferric oxide nanocomposites. Talanta. 2012;89:417-421.

136. Woo S, Kim YR, Chung TD, Piao Y, Kim H. Synthesis of a graphenecarbon nanotube composite and its electrochemical sensing of hydrogen peroxide. Electrochimica Acta. 2012;59:509-514.

137. Zhang Y, Sun XM, Zhu LZ, Shen HB, Jia NQ. Electrochemical sensing based on graphene oxide/Prussian blue hybrid film modified electrode. Electrochimica Acta. 2011;56(3):1239-1245.

138. Devaramani S, Malingappa P. Synthesis and characterization of cobalt nitroprusside nano particles: Application to sulfite sensing in food and water samples. Electrochimica Acta. 2012;85:579-587.

139. Chai C, Takhistov P. Label-free toxin detection by means of timeresolved electrochemical impedance spectroscopy. Sensors (Basel). 2010;10(1):655-669. 
140. MaXY, Chen MF. Electrochemical sensor based on graphene doped gold nanoparticles modified electrode for detection of diethylstilboestrol. Sensors and Actuators B: Chemical. 2015;215:445-450.

141. Li Z, Sheng C. Nanosensors for food safety. J Nanosci Nanotechnol. 2014;14(1):905-912.

142. Wu BQ, Kumar A. Extreme ultraviolet lithography and three dimensional integrated circuit-A review. Appl Phys Rev. 2014;1(1):15.
143. Khan S, Lorenzelli L, Dahiya RS. Technologies for Printing Sensors and Electronics Over Large Flexible Substrates: A Review. IEEE Sensors Journal. 2015;15(6):3164-3185.

144. Chen Y. Applications of nanoimprint lithography/hot embossing: a review. Applied Physics A. 2015;121(2):451-465.

Reports in Electrochemistry

\section{Publish your work in this journal}

Reports in Electrochemistry is an international, peer-reviewed, open access journal publishing original research, reports, reviews and commentaries on all areas of electrochemistry. The manuscript management system is completely online and includes a very quick and fair peer-

review system. Visit http://www.dovepress.com/testimonials.php to read real quotes from published authors. 